\title{
Primary amenorrhoea - a single centre experience of 38 cases
}

\author{
Balampa $\mathbf{P}^{1}$, Rabindran ${ }^{2}$, Pavani $^{3}$ \\ ${ }^{1}$ Senior Consultant Gynaecologist, ${ }^{2}$ Consultant Neonatologist, ${ }^{3}$ Consultant Gynaecologist, Sunrise Superspeciality \\ Hospital, Hyderabad, AP, India
}

Address for Correspondence: Dr Rabindran, Email: rabindranindia@yahoo.co.in

\begin{abstract}
Introduction: Primary amenorrhoea is defined as absence of menstruation by the age of 14 in absence of secondary sexual characteristics \& by age 16 regardless of the presence or absence of secondary sexual characteristics. It occurs in around $1-4 \%$ of women in reproductive age group. The common causes of primary amenorrhoea include outflow tract disorders or uterine abnormalities, ovarian disorders, pituitary dysfunction, and hypothalamic dysfunction. The data of primaryamenorrhoea from our country is limited due to poor reporting and frequent loss to follow up. Hence we undertook this prospective study to determine the etiology for primary amenorrhoeabased on clinical examination and laboratory investigations. Methodology: This prospective study was done in Gynecologic Clinic of Sunrise Hospital between August 2013 to May 2015. The work up of primary amenorrhoea patients comprised of 1) History taking 2) Physical examination 3) Laboratory investigations. Patients were classified into 5 groups based on the compartment of organs involved.I- End organ failure/ outflow tract obstruction, II- Gonadal failure, III- Pituitary cause, IVHypothalamic cause, V- Other causes. Results: In our study, the 2 most common etiologic factors of primary amenorrhoeawere mullerian agenesis $(65.78 \%)$ and gonadal dysgenesis (21.05\%).Hypogonadotrophichypogonadism was noted in $10.52 \%$ of cases. Range of average age of the patients when they first consulted the physician was 14 to 33 years. Conclusion: Prompt reporting and awareness of available treatment options based on the etiology can make a huge difference in this often underreported disorder.
\end{abstract}

Key words: Primary Amenorrhea, Müllerian Agenesis, Gonadal, Dysgenesis .

\section{Introduction}

Primary amenorrhoea is defined as absence of menstruation by the age of 14 in absence of secondary sexual characteristics \& by age 16 regardless of the presence or absence of secondary sexual characteristics [1]. Maturation of hypothalamus, anterior pituitary, ovary \& reproductive tract results in establishment of normal menstruation. Amenorrhoea results due to break in one or more places in this chain. The causes of primary amenorrhoeainclude outflow tract disorders or uterine abnormalities, ovarian disorders, pituitary dysfunction and hypothalamic dysfunction. The absence of secondary sexual characteristics indicates either hypothalamic-pituitary axis dysfunction or gonadal dysgenesis. Amenorrhoea occurring in the presence of normalsecondary sexual characteristics points to a problem with menstrual outflow such as imperforate hymen orabsence of uterus or vagina.

The prevalence of Primary Amenorrhoea is around 1-4

Manuscript Received: $4^{\text {th }}$ Sept 2015

Reviewed: $16^{\text {th }}$ Sept 2015

Author Corrected: $20^{\text {th }}$ Sept 2015

Accepted for Publication: $30^{\text {th }}$ Sept 2015
$\%$ of women in reproductive age group [2,3,4]. Despite the low prevalence of primary amenorrhoea, a prompt, comprehensive assessment by a consultant in reproductive medicine is warranted, as amenorrhoea is often the presenting sign of an underlying reproductive disorder. A delay in diagnosis and treatment may adversely impact the long-term future of such patients.

Although primary amenorrhoea has long been recognized, there are not many studies on large numbers of patients. Majority of papers are case reports and some are based on a small series of patients. Apart from these the etiologic causes may vary from area to area due to different racial group of patients. Since there are few large series on this topic from our country, the present study was undertaken to determine the etiologic factors responsible for primary amenorrhoea. 


\section{Objective}

To determine the etiologic factors responsible for primary amenorrhoea on the basis of clinical examination and laboratory investigations.

\section{Material \& Methods}

This prospective study was done in a private setting among patients who attended the Gynecologic Clinic of Sunrise Hospital between August 2013 \& May 2015. The study protocol was approved by the Institutional Ethics committee. The work up of primary amenorrhoea patients comprised of 1) History taking including chief

\section{Original Research Article}

complaint, present history, past history \& family history; 2) Physical examination including general examination, rectal and/or pelvic examination \&transabdominal pelvic ultrasonography; 3) Laboratory investigations depending on the provisional diagnosis derived from history \& physical examination. Patients were classified into 5 groups based on the compartment of organs involved.

I- $\quad$ End organ failure/ outflow tract obstruction

II- Gonadal failure

III- Pituitary cause

IV- Hypothalamic cause

V- Other causes.

\section{Results}

During the study period, 38 cases of primary amenorrhoea were analyzed.Two most common etiologic factors were mullerian agenesis (65.78\%) and gonadal dysgenesis (21.05\%).Hypogonadotrophichypogonadism was noted in $10.52 \%$ of cases.Hyperprolactinemia was noted in 1 case. Range of average age of the patients when they first consulted the physician varied between 14 to 33 years. Karyotyping was done on 8cases of gonadal dysgenesis and 46 XX karyotype was found in $75 \%$ and $45 \mathrm{XO}$ in $25 \%$ of analyzed cases.

Distribution of Primary Amenorrhoea

\begin{tabular}{|c|c|}
\hline CAUSES & No. \\
\hline \multicolumn{2}{|l|}{ GROUP I- END ORGAN FAILURE/ OUTFLOW TRACT OBSTRUCTION } \\
\hline Mullerian Agenesis & 25 \\
\hline Transverse vaginal septum & 0 \\
\hline Tuberculousendometritis & 0 \\
\hline $\begin{array}{l}\text { Male pseudo hermaphroditism } \\
\text { - complete testicular feminization }\end{array}$ & 0 \\
\hline \multicolumn{2}{|l|}{ GROUP II- GONADAL FAILURE } \\
\hline Gonadal dysgenesis ( $46 \mathrm{XX}$ ) & 6 \\
\hline Gonadal dysgenesis (45XO, Mosaic) & 2 \\
\hline Agonadism & 0 \\
\hline Post chemotherapy. & 0 \\
\hline \multicolumn{2}{|l|}{ GROUP III- PITUITARY CAUSE } \\
\hline Hyperprolactinemia & 1 \\
\hline Prolactinoma & 0 \\
\hline \multicolumn{2}{|l|}{ GROUP IV } \\
\hline Hypogonadotropichypogonadism & 4 \\
\hline Hypothalamic dysfunction & 0 \\
\hline \multicolumn{2}{|l|}{ OTHERS } \\
\hline Primary hypothyroidism & 0 \\
\hline Congenital adrenal hyperplasia & 0 \\
\hline Androgen secreting tumour & 0 \\
\hline
\end{tabular}




\section{Original Research Article}

\section{Discussion}

Amenorrhoeais not a diagnosis but a symptom of a physiological or pathophysiological process. Physiological causes of primary amenorrhoea include pregnancy and late puberty and thesewill not need treatment. As for gynaecologicalreasons, congenital and acquired anomalies in the structureof the uterus and vagina can cause pathological amenorrhoea. The prevalence of Primary Amenorrhoea is around 1-4 \% of women in reproductive age group [2,3,4].

The pathophysiology of a normal menstrual cycle is complex involving multiple axes including the hypothalamus, pituitary, ovary, uterine smooth muscles and arterioles of the endometrium. The hypothalamus secretes GnRH, which travels down the anterior portion of the pituitary via the hypophyseal portal system and binds to receptors on the secretory cells of the adenohypophysis. In response to $\mathrm{GnRH}$ stimulation these cells produce $\mathrm{LH}$ and FSH, which activates the ovaries to produce estrogen and inhibin which regulate the menstrual cycle and ovarian cycle $[5,6]$. When all the axes including the hormonal secretions by target organs are maintained, amenorrhea can be secondary to loss of vascular integrity in the spiral arterioles of the endometrium.

The pathophysiology of primary amenorrhoea can be better understood by the embryologic development. The uterus, cervix and upper two thirds of the vagina are formed from the coelomic derived paramesonephric ducts in the third month of development. In the absence of anti-Müllerian hormone the paired paramesonephric structures adhere and connect to the sinus tubercle. The ducts fuse together from their caudal tops forming a single lumen known as the uterovaginal canal. The uterovaginal canal develops into the uterus and superior section of the vagina, while the cranial unfused tips form the fallopian tubes with the infundibula at the open ends of the ducts. The reason and mechanism behind the failure of the paramesonephric ducts to fuse or develop in some women is not clearly understood. Various hypotheses have been suggested including teratogenic insult and maternal infection. Mullerian agenesis (Mayer-Rokitansky-Küster-Hauser syndrome) affects about 1 in 5,000 newborn females [7].

The etiologic factors of primary amenorrhoea include

Group I- End organ failure/ outflow tract obstruction a) Mullerian agenesis

b) Transverse vaginal septum

c) Tuberculousendometritis

d) Male pseudo hermaphroditism- complete testicular feminization.

Group II- Gonadal failure

a) Gonadal dysgenesis (46XX, 45XO,Mosaic)

b) Agonadism

c) Post chemotherapy.

Group III- Pituitary cause

a) Hyperprolactinemia

b) Prolactinoma.

Group IV

a) Hypogonadotropichypogonadism

b) Hypothalamic dysfunction.

Group V

a) Primary hypothyroidism

b) Congenital adrenal hyperplasia

c) Androgen secreting tumour

The most common cause of primary amenorrhoea in our study population was mullerian agenesis. About 65.78 $\%$ cases of primary amenorrhoea had mullerian agenesis which was higher than the studies by Quorrata et al., [8] \& Prasong et al., [9] who reported mullerian agenesis in $36.3 \% \& 39.7 \%$ of cases of primary amenorrhoea respectively.Müllerian agenesis was also the most common cause of primary amenorrhoea in studies by Rattanachaiyanont M et al.,[10], Rao K et al., [11] \& Kumar A et al.,[12]. Mullerian agenesis patients present with primary amenorrhoea, and are usually found to have an absent or rudimentary vagina, and an absence of the uterus and fallopian tubes.Ovarian function is normal and patients have normal development of secondary sexual characteristics.

Gonadal dysgenesiswas noted in $21.05 \%$ of our cases of primary amenorrhoeawhich was comparable to 29.05 $\%$ in the study by Quorrata et al [8] \& $35.3 \%$ in the study by Prasong et al, [9]. Reindollaret al. in his study showed that the most common cause of primary amenorrhoea in the American population was gonadal dysgenesis (48.5\%) [13].

We noted hypogonadotrophic Hypogonadism in 10.52 $\%$ of our cases which was similar to the study by Prasong et al., [9]. Karyotyping was done on 8 cases of 
gonadal dysgenesis. 46, XX karyotype was found in $75 \%$ of analysed cases, as compared to $50 \%$ in the study by Quorrata et al., [8] and 45 XO was noted in $25 \%$ as compared to $10 \%$ in the study by Quorrata et al., [8] \& $35.59 \%$ in the study by Prasong et al., [9]. The most common cause was chromosomal abnormality $(24 \%$ ) in a study by James H Evans et al.,[14]. Range of average age of the patients when they first consulted the physician was between 14to 33 years which was comparable to the study by Quorrata et al.,[8]

The approach towards primary amenorrhoea starts with a carefully obtained History. Physical examination focusing on body composition (weight), the presence or absence of breast development and the presence of a uterus is important. Additional laboratory examination and imaging (ultrasound and/or laparoscopy) help in prompt management.

\section{Conclusion}

The etiologic causes of primary amenorrhoea in our study are different from earlier reports. Racial and environmental differences, facilities for diagnostic tools may contribute to these differences. As diagnosis based on inadequate data may be misleading, both clinical examinations \& laboratory investigations have to be completed before final diagnosis of primary amenorrhoeais established. Early recognition of the definite etiology and institution of the appropriate treatment will minimize late complications.

Conflict of interest: None declared.

Funding: Nil, Permission from IRB: Yes

\section{Reference}

1. Donelle Laugh Lin, Ian H. Thorneycroft. Amenorrhoea; Current- Obstetric and gynecologic diagnosis and treatment, 9th Edition- 2002, page- 991.

2. S.S. Ratnam, R. JothiKumar.Amenorrhoea, Obstetric and gynecology for post graduate. $2^{\text {nd }}$ Edition-1999; Vol.-1, Page- 241

3. Bachmann GA, Kemmann E. Prevalence of oligomenorrhea and amenorrhea in a college population.Am J Obstet Gynecol. 1982 Sep 1;144(1):98-102.

4. Pettersson F, Fries H, Nillius SJ. Epidemiology of secondary amenorrhea: incidence and prevalence rates. Am J Obstet Gynecol. 1973;117:80-86.

\section{Original Research Article}

5. Master-Hunter $\mathrm{T}$,Heiman DL. Amenorrhea: Evaluation and treatment. Am Fam Physician 2006 Apr 15; 73(8): 1374-1382.

6. Meethal SV, Liu T, Chan HW, Ginsburg E, Wilson AC, Gray DN, Bowen RL, Vonderhaar BK, Atwood CS.. Identification of a regulatory loop for the synthesis of neurosteroids: A steroidogenic acute regulatory protein-dependent mechanism involving hypothalamicpituitary-gonadal axis receptors. J Neurochem2009 Aug;110(3):1014-27. doi: 10.1111/j.14714159.2009.06192.x.

7. Aittomäki K, Eroila H, KajanojaP .A populationbased study of the incidence of müllerian aplasia in Finland.FertilSteril 2001 Sep;76(3):624-5.

8. QuorrataEynulForhad, SumayyaTasnim ,Anowara Begum. Primary Amenorrhoea - Analysis of 44 cases; Bangladesh J ObstetGynaecol, 2008; Vol. 23(2) : 46-50. DOI: http://dx.doi.org/10.3329/bjog.v23i2.4958.

9. PrasongTanmahasamut, ManeeRattanachaiyanont, ChongdeeDangrat, SuchadaIndhavivadhana, Surasak Angsuwattana and KitiratTechatraisak. Causes of primary amenorrhea: A report of 295 casesin Thailand; J. Obstet. Gynaecol. Res. Vol. 38, No. 1: 297-301, January 2012; doi:10.1111/j.1447-0756.2011.01677.x.

10. Rattanachaiyanont $\mathrm{M}$, Kunathikom $\mathrm{S}$, Angsuwattana S, Techatraisak K, Mekmahan O, Karavagul C, Ko-Anantakul S. Primary amenorrhoea: A retrospective study at Siriraj Hospital. J Med Assoc Thai 1997 Oct; 80(10): 619-25.

11. Rao K, Pillai NV. Primary amenorrhoea (analysis of 40 cases).J Indian Med Assoc 1991; 89: 42-43.

12 Kumar A, Mittal S. Primary amenorrhoea: Analysis of 48 cases. J Indian Med Assoc. 1998 Apr; 96(4): 11920.

13. Reindollar RH, Tho SPT, McDonough PG. Delayed puberty: An update study of 326 patients. Trans Am GynecolObstetSoc 1989; 8: 146-162.

14. James H. Evans; Aust. N.Z. J. Review of 50 Cases of Primary Amenorrhoea. Obstet. Gynaecol. 1971 11( 7) pg 7-12.DOI: 10.1111/j.1479-828X.1971.tb00443.x. 
Original Research Article

How to cite this article?

Balampa P, Rabindran, Pavani. Primary amenorrhoea - a single centre experience of 38 cases. Obs Rev: Jobstet Gynecol 2015;1(1):9-13. doi: 10.17511/joog.2015.i01.03. 